\title{
The cost load regulation and management of electrical energy by directions of impact on the components of total price
}

\author{
Alexey Pleshkov ${ }^{1, *}$, Aleksey Kopylov ${ }^{2}$, and Petr Ulyankin ${ }^{3}$ \\ ${ }^{1}$ Energostroy LLC, Kaliningrad, Russian Federation \\ ${ }^{2}$ State enterprise of the Kaliningrad region «Edinaya sistema obrascheniya s othodamy», Kaliningrad, \\ Russian Federation \\ ${ }^{3}$ Western Branch of RANEPA, ME\&S Department, Kaliningrad, Russian Federation
}

\begin{abstract}
The issues of optimizing regional pricing are especially acute for the Kaliningrad Region due to its exclave features. At the same time, the cost of energy resources has become one of the main issues in making managerial decisions. Recently, the so-called Technoparks have become one of the new forms of organizing the production process in a certain branch of industry, or a process that is at the junction of several branches. There are a variety of descriptions of the indisputable advantages of this work format for a specific technological process, however, the possibilities in the field of reducing the costs of consumed energy resources that arise with such a local siting of production are not discussed that often. According to the authors of the article, based on the structure of the tariff, it is possible to classify methods of reducing the cost price by the impact on the components of the final cost of energy supply services. It should be noted that the classification sign of saving methods will be precisely the component of the tariff, while the methods themselves can be aimed both at reducing the price expression of each component of the tariff and at the volume of services for this component. The authors have also identified regional features of the pricing processes in the energy industry.
\end{abstract}

\section{Introduction}

The transition period of the domestic industry from a planned economy to a market economy has raised the issue of the struggle for production costs for manufacturers. The inclusion of Russia in the global market and the need to fight competitors for a consumer made it necessary to formulate the requirements for each cost item in a new way, and the cost of energy resources became one of the main issues when making managerial decisions: the share of costs for the purchase of energy resources in the cost price of products of Russian manufacturers reaches $10 \%$, while for several industries, the share of costs for electric energy in the total cost structure is more than twice that of Western competitors (1). For example, this share is about $5 \%$ in such developed countries of the European Union as Italy, which, of

\footnotetext{
*CCorresponding author: alexey_pleshkov@mail.ru
} 
course, is partly due to the peculiarities of the production technology, but the price of electricity is also an important factor (2).

At the beginning of the 21 st century, the liberalization of the electricity market began in Russia, which was supposed to create opportunities for competition in this market of various participants, which, according to the reformers plan, was to make the relations of all stakeholders more transparent, the work of energy companies more efficient, and the constant growth of the tariff burden on consumers replaced with a market mechanism of price formation based on the balance of supply and demand. The formal start for the operation of the Power Joint Market was the Decree of the Government of the Russian Federation No. 529 of August 31, 2006, "On Improving the Functioning of the Wholesale Power Joint Market."

\section{Research Methodology}

During the work, such general scientific methods and techniques as analysis and synthesis, induction and deduction, as well as statistical methods were used. Together, they ensured the reliability of economic and comparative analysis and the validity of the conclusions.

This work was based on scientific articles of domestic and foreign researchers and specialists, statistical digests, materials from the domestic business press and websites.

\section{Findings}

Analysis of the progress of the electricity market reform and its results is not a topic for this article, however, we will dwell on its main result - an unregulated price that underlies any bill for electricity consumers. Note that about $80 \%$ of electricity is sold at an unregulated price (3), and the population purchases electricity at regulated tariffs, they operate outside of market mechanisms, this is about $15 \%$ of all volumes of electricity sold (4), the rest is sold using competitive models to one degree or another.

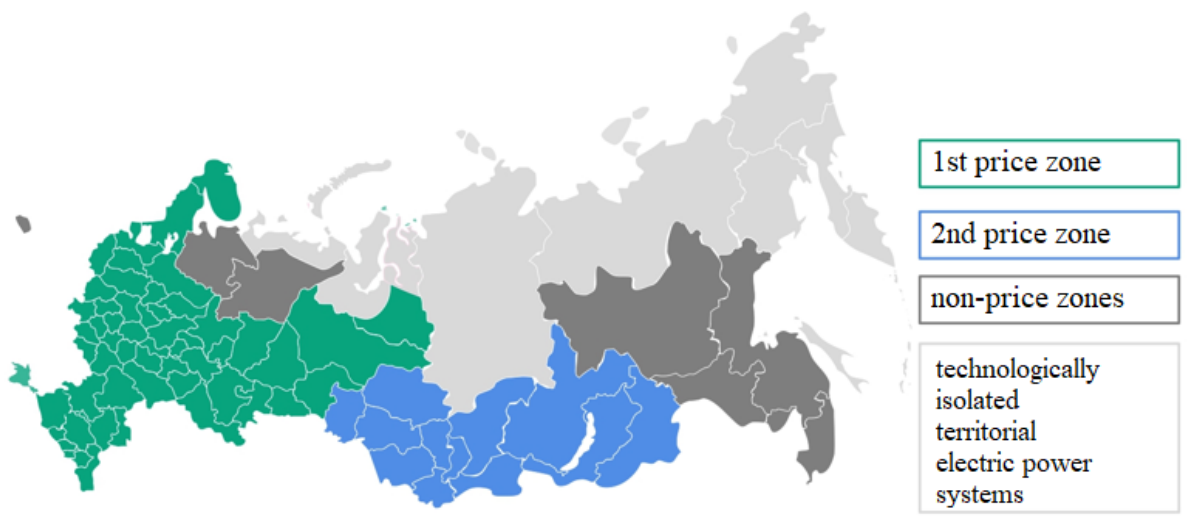

Fig. 1. Electricity market structure in Russia (5).

The division of the territories of the Russian Federation into zones with different conditions for the functioning of the wholesale market for electricity and power is determined by the Decree of the Government of the Russian Federation dated December 27, 2010, No. 1172 (as amended of March 18, 2021) "On Approval of the Rules for the Wholesale Market for Electricity and Power and on Amending Certain Acts of the Government of the Russian Federation on Issues of Organizing the Functioning of the Wholesale Market for Electricity 
and Power" (hereinafter - the "WMEP Rules"). The same normative document generally describes the procedure for the operation of WMEP subjects and the rules for price formation. The Kaliningrad Region is classified by the WMEP Rules as non-price zones of the WMEP, in other words, the wholesale market is functioning, but prices are regulated due to the peculiarities of the regional power system, almost all instruments of interaction with the WMEP are available to consumers of the Kaliningrad Region.

Recently, the so-called Technoparks have become one of the new forms of organizing the production process in a certain branch of industry, or a process that is at the junction of several branches. There are many descriptions of the indisputable advantages of this work format for a specific technological process, however, the opportunities in the field of reducing the costs of consumed energy resources that such a local location of production provide are not mentioned that often.

Before proceeding to specific proposals for the use of the unique technological infrastructure of technoparks to optimize the electricity cost, it is necessary to briefly describe the structure of the final tariff, since each cost optimization method is aimed at reducing the value of one of the components of this tariff and such a description will help to more easily perceive the cause and the investigative relationship between measures and the result of savings.

The main documents governing the procedure for establishing electricity tariffs are:

- Federal Law No. 35-FZ dated March 26, 2003, “On the Electric Power Industry";

- Decree of the Government of the Russian Federation dated December 29, 2011, No. 1178 "On Pricing in the Field of Regulated Prices (Tariffs) in the Electric Power Industry";

- Order of the FTS of Russia dated September 16, 2014, No. 1442-e "On Approval of the Methodological Guidelines for the Calculation of Electricity (power) Tariffs for the Population and Equated Categories of Consumers, Tariffs for Services for the Transmission of Electricity Supplied to the Population and Equated Categories Consumers"

Currently, according to the legislation, tariffs (prices) for electric energy in the Kaliningrad Region are the sum of the following components (6):

1. "WMEP Price": the average weighted regulated price for electric energy (power) purchased by the energy sales organization on the wholesale electricity market (hereinafter "WMEP") in the non-price zone (monthly calculated by the Guaranteeing Supplier based on the parameters provided by AO "ATS");

2. "Infrastructure payments": The cost of services of the commercial operator AO "ATS", the cost of the services of the system operator AO "SO UPS", and the cost of the integrated service of the AO "CFR" (set by the FAS Russia);

3. "Network component": The cost of services for the transmission of electrical energy through regional networks (set by the State Regulation of Prices and Tariffs of the Kaliningrad Region within the limits approved by the FAS Russia);

4. "Sales markup": The sales markup of the guaranteeing supplier (set by the State Regulation of Prices and Tariffs of the Kaliningrad Region); 
TARIFF STRUCTURE JANUARY 2020

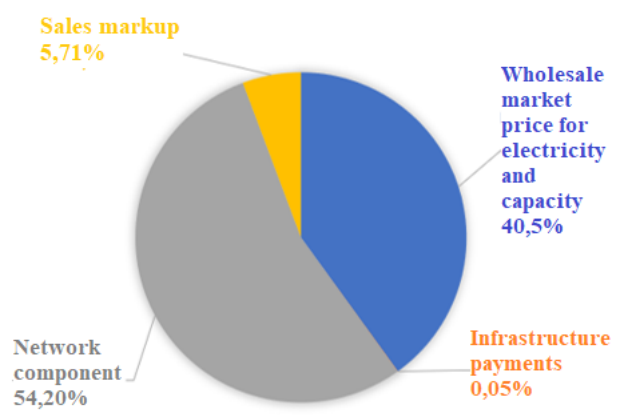

TARIFF STRUCTURE JANUARY 2021

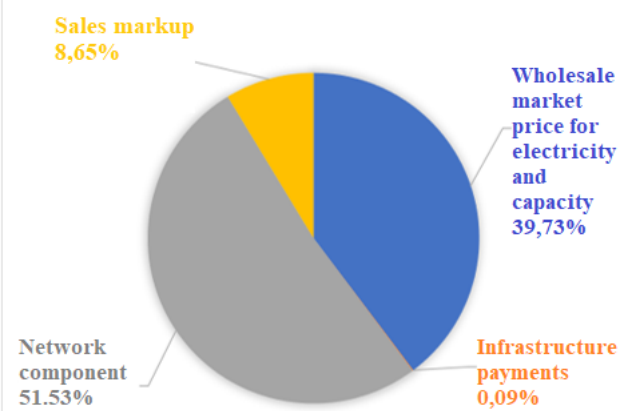

Fig. 2. Structural diagram of the components of the electricity tariff for the most "popular" LV level among consumers and with a capacity of up to $670 \mathrm{~kW}$.

Let's consider ways to directly control the cost of electrical energy. Based on the structure of the tariff and neglecting infrastructure payments due to their insignificance, we consider it expedient to classify ways to reduce the cost in terms of impact on the components of the final cost of energy supply services. It should be noted that the classification sign of saving methods will be precisely the component of the tariff, while the methods themselves can be aimed both at reducing the price expression of each component of the tariff and at the volume of services for this component.

I. Working with the "WMEP Price":

1) Switching to a two-part tariff when determining the "WMEP Price".

The use of a two-part tariff allows paying a lower cost of electricity purchased from the WMEP, on the condition of load control.

2) Organization of a system for managing the amount of hourly consumption during the maximum hours of the actual peak load.

II. Working with the "Network component":

1) Switching to a two-part tariff when determining the "Network component"

The use of a two-part tariff allows reducing the cost of electricity transmission services in the final price, on the condition of load control.

2) A set of technical measures that allow changing the "Design voltage level" characteristic, which significantly affects the value of the final price for the consumer.

III. Working with "Sales markup"

Purchase of electrical energy in the WMEP.

As can be seen from the proposed classification given in the list mentioned above, the only component that cannot be influenced is Infrastructure payments - the cost of these services is set universal for all participants in the electricity market, and, unfortunately, the state has not provided consumers with tools to manage the price of these services, the only thing that can be noted is that their value does not amount to hundredths of a percent of the final price and is unlikely to drastically affect the cost of production, unlike other components.

Next, we will describe in more detail the content of each of the possible measures and their possible effects.

\subsection{Switching to a double-part tariff when determining the "WMEP Price"}

Article 5 of the Federal Law "On the Electric Power Industry" dated March 26, 2003, No, $35-\mathrm{FZ}$ says that the economic basis for the functioning of the electric power industry is the 
system of relations related to the production and turnover of electricity and power in the wholesale and retail markets, conditioned by the technological features of the functioning of electric power facilities. There is competitive electricity and power market in the Russian Federation, where the price is formed based on the supply parameters generated by electricity-generating enterprises and the demand generated by a pool of large electricity consumers, which consists mainly of guaranteeing suppliers, energy sales organizations, and large industrial consumers. Therefore, unregulated prices in the WMEP are formed in most of the country's territory, which, based on the results of trading, are transmitted to retail markets, where they are already used in payments for small consumers and the population. And although the Kaliningrad Region is allocated to the WMEP non-price zone, and prices here are called regulated, they still change every month, and market mechanisms are involved in their formation.

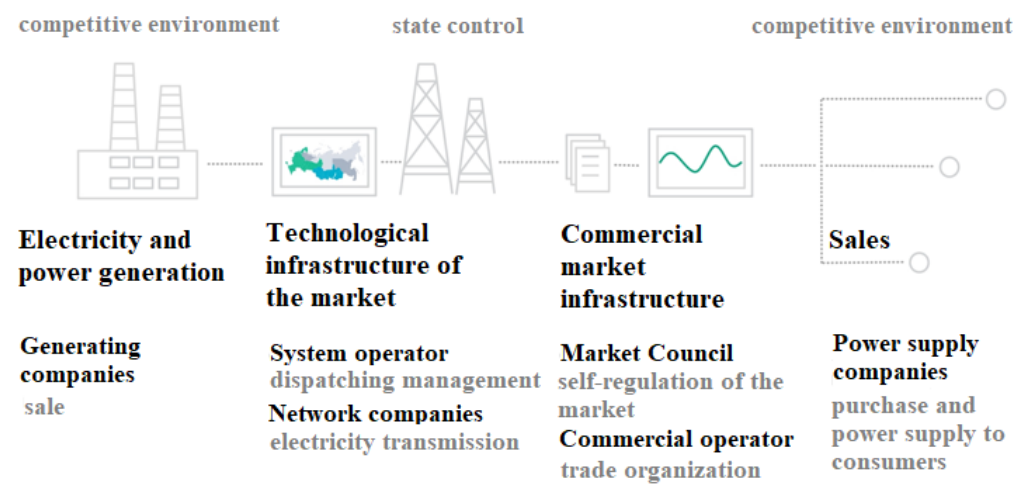

Fig. 3. Competitive and regulated zones of the electricity supply process (7)

Precisely because the price is formed based on several variable parameters, the final price for the consumer must be calculated every month based on the results of market trades, therefore the value of the Average Weighted Regulated Price for Electricity (Power) is calculated by the Guaranteeing Supplier, but initially, this price consists of this price for power (in the professional community of Kaliningrad, this is usually called "Generator" power) and prices for electric energy of the WMEP. The current legislation offers ways for the consumer to select a one-part or two-part tariff for the "WMEP Price" when concluding an energy supply agreement, two-part tariffs for determining the WMEP Price offer price categories from 3 to 6 , the choice of which is made by the consumer when concluding an energy supply agreement, or when changing the price category in future.

The two-part tariff for the "WMEP Price" determines the consumer's obligations to pay for Generator power at the so-called maximum hours of the actual peak load, which are brought to the attention of consumers each month after the end of the billing period. Liabilities are defined as the product of price parameters multiplied by the value of Generator power. These hours reflect the time of peak consumption of electricity and power in the region over the past month, respectively, during these hours the cost of electricity and power is at maximum. At first glance, it may seem that the timing of providing the value of the maximum hours of the actual peak load after the end of the billing period deprives the consumer of the ability to control the process, but this is not entirely true, the fact is that the data on this parameter has a sufficient history of statistics for forecasting with high accuracy and more importantly this hour is almost always within the planned peak hours of the Kaliningrad Region, which are approved for the calendar year ahead of System Operator of the Unified Power System (AO "SO UPS"). Thus, the specified process can be controlled by adjusting the technological lines to this logic if necessary, but we will talk about this in more 
detail in future works, and we will finish this section with a description of the benefits of a choice from 3 to 6 price categories for the consumer without additional actions.

Table 1. Planned peak hours for the Kaliningrad Region, 2021 (8)

\begin{tabular}{|c|c|c|c|c|c|c|c|c|c|c|c|c|}
\hline & January & February & March & April & May & June & July & August & September & October & November & December \\
\hline $\begin{array}{c}\text { For the } \\
\text { Kaliningrad } \\
\text { region }\end{array}$ & $\begin{array}{l}\text { 11th to } \\
15 \text { th } \\
\text { and from } \\
19 \text { th to } \\
21 \text { st hours }\end{array}$ & $\begin{array}{l}\text { 10th to 13th } \\
\text { and from } \\
\text { 20th to } 22 s t \\
\text { hours }\end{array}$ & $\begin{array}{l}11 \text { th to } \\
12 \text { th } \\
\text { and } \\
\text { from } \\
22 \text { th to } \\
23 \text { st } \\
\text { hours }\end{array}$ & $\begin{array}{l}\text { 10th } \\
\text { to } \\
\text { 13th } \\
\text { and } \\
\text { from } \\
22 \text { th } \\
\text { to 23st } \\
\text { hours }\end{array}$ & $\begin{array}{c}\text { from } \\
11 \text { to } \\
17 \\
\text { and to } \\
23 \\
\text { hours }\end{array}$ & $\begin{array}{l}\text { from } \\
11 \text { to } \\
16 \\
\text { hours }\end{array}$ & $\begin{array}{c}\text { from } \\
11 \text { to } \\
16 \\
\text { hours }\end{array}$ & $\begin{array}{l}\text { from } 11 \\
\text { to } 17 \\
\text { and to } \\
19 \text { hours }\end{array}$ & $\begin{array}{l}\text { 11th to 13th } \\
\text { and from 21th } \\
\text { to 23st hours }\end{array}$ & $\begin{array}{l}\text { from } 20 \text { to } \\
22 \text { hours }\end{array}$ & $\begin{array}{l}\text { 11th to 12th } \\
\text { and from } \\
19 \text { th to } 22 \mathrm{st} \\
\text { hours }\end{array}$ & $\begin{array}{l}\text { 11th to 13th } \\
\text { and from } \\
19 \text { th to } 22 \text { st } \\
\text { hours }\end{array}$ \\
\hline
\end{tabular}

The fact is that the net electricity supply to end consumers in the Kaliningrad Region consists of at least one-third of the consumption of the population, which significantly affects the nature of the load schedule of the region. This translates into the fact that in the autumnwinter period, the actual peak of the load comes to almost all working days in the evening: from 7 PM to 9 PM, it is at this time that the WMEP Price is the highest, i.e. if the peak of energy consumption of your technological process does not coincide with the maximum electricity consumption in the region, then the choice of price categories from 3 to 6 is already capable of reducing the specific cost of $\mathrm{kWh}$ for your cost price. The situation is the opposite in summer and if you do not control the consumption process, you can even get a negative effect, therefore, once choosing the path of two-part tariffs, you still need to analyze and manage daily consumption schedules.

\subsection{Organization of a system for managing the amount of hourly consumption during the maximum hours of the actual peak load}

The proposals in this section have already been described above, however, we will try to cover some points in more detail. So, the choice of a two-part tariff for determining the "WMEP Price" has already created some savings for you, but it makes sense not to stop there and create a load schedule management system at the enterprise. Based on the statistics of the values of the actual peak load maximum hours for several previous years (it has been available in the Kaliningrad Region since 2016), as well as applying data on the planned peak hours of the Kaliningrad Region, it is possible to determine the time intervals on working days of the next year (or even more long-term planning) and set the task for technicians to develop an action plan to reduce energy consumption at this time. This can be the movement of work shifts, technological breaks, planning of non-energy-intensive types of work for a given time, etc. Of course, not every production can afford this, however, it is obvious that such an analysis is useful and can bring real savings to the company.

\subsection{Switching to a two-part tariff when determining the "Network component"}

The tariff for electricity transmission services is established by the State Regulation of Prices and Tariffs of the Kaliningrad Region in two terms: one-part and two-part. With a one-part tariff, the consumer's obligations are defined as the product of the volume of electricity consumption multiplied by the tariff, thus, the consumer here can only save by consuming less, which is often inappropriate for the technological process.

At the same time, with a two-part tariff, the main part of the final price is the cost of the calculated power (in the professional community it is called "Transport" power), which is calculated as the product of the tariff for the Transport power multiplied by the power value, calculated as the arithmetic value of the maximum values for each working day of the billing period at the established planned peak hours of the Kaliningrad Region. The planned peak hours of the Kaliningrad Region are annually set by the Joint Stock Company System Operator of the Unified Power System (AO "SO UPS"). 
Thus, as already described above, it is possible to significantly reduce the estimated power value when changing the technological processes and decreasing power consumption during peak consumption hours, which reflects the specific cost of maintaining electrical networks.

\subsection{A set of technical measures that allow changing the "Design voltage level" characteristic, which significantly affects the value of the final price for the consumer}

It is quite obvious that the cost of a network company differs significantly when transferring electricity to a plant connected from a high-voltage line, or to a small store located in an apartment building. The difference in these costs is reflected in the "Estimated voltage level" parameter, which increases the final tariff the more, the lower the voltage level at which the consumer is connected. This is due, among other things, to the fact that bringing electric energy to the consumer at a voltage level of $0.4 \mathrm{kV}$ requires significantly more electrical equipment than for the same at a voltage level of $110 \mathrm{kV}$.

Thus, the meaning of the proposed measure is to analyze the existing technical capabilities and carry out a number of measures to connect the consumer's facility at a higher voltage level, which will reduce the tariff for the transmission of electrical energy. For example, the value of the rate for the maintenance of electric networks of the two-part tariff in the 1st half of 2021 at the LV voltage level is $132 \%$ higher than at the HV voltage level, and the value of the one-part tariff at the LV voltage level is $166 \%$ higher than at the HV voltage level. Working with this indicator usually yields the most noticeable results in terms of reducing the cost burden on the consumer.

Table 2. Comparison of the cost of services for the transmission of electrical energy in one-part terms for different voltage levels, RUB/MWh.

\begin{tabular}{|c|c|c|}
\hline $\begin{array}{c}\text { Voltage } \\
\text { level }\end{array}$ & 1 st half of 2021 & 2nd half of 2021 \\
\hline \multirow[t]{2}{*}{ HV } & $1,489.49$ & $1,636.73$ \\
\hline & $+41.98 \%$ & $+42 \%$ \\
\hline \multirow[t]{2}{*}{$\mathrm{CH}-2$} & $2,114.72$ & $2,324.24$ \\
\hline & $+87.29 \%$ & $+87.23 \%$ \\
\hline LV & $3,960.75$ & $4,351.73$ \\
\hline
\end{tabular}

In this case, specific measures will be the implementation of work on the construction of the own energy infrastructure facilities, allowing to connect to the network of the network company at a voltage level of at least $110 \mathrm{kV}$, which corresponds to the calculated HV voltage level.

\subsection{Purchase of electrical energy in the WMEP}

As described above, Russia has implemented the concept of a competitive electric energy and power market, which is expressed in the sale of electric energy and power on the wholesale market, which makes it possible to form the "WMEP Price" based on the results of competitive bidding, and then electric energy is sold on the retail market where, depending on the supplier, you can choose a higher or lower "Sales markup" - the cost of services for the sale of electrical energy to consumers of a supplier of last resort or an energy sales 
organization. Typically, the Guaranteeing supplier has the highest Sales Margin, as it serves a large volume of citizen customers, which forces it to bear the increased costs of setting up large reception offices and advanced services for receiving payments and delivering invoices. Therefore, the number of consumers who choose private energy sales companies to save on the "Sales markup" is increasing annually.

Access to the WMEP is allowed for consumers who meet the requirements established by the current legislation (9), if the specified requirements are met, the consumer can enter the WMEP either independently or with the help of a commercial energy sales company. For any of the above-mentioned methods, the registration of the "Delivery point cluster" of the consumer in the WMEP takes place. A delivery point cluster (DPC) - one or more delivery points related to one node of the design model and/or to a single technologically indivisible energy facility and limiting the territory in relation to which the purchase and sale of electrical energy (power) on the wholesale market is carried out only by this participant, and used to determine and fulfill the obligations of the wholesale market participant related to the supply and payment of electricity (power).

If a consumer entered the WMEP independently, then the costs of paying for the "Sales markup" disappear completely and are transformed into the cost of remuneration of personnel who interacts with the WMEP. These costs are usually substantially less than the "Sales markup".

If the consumer works in the WMEP through a private energy sales company, then the "Sales markup" remains, but now it reflects not the costs of the Guarantee Supplier to ensure the supply of electricity, but the costs of the already mentioned private energy sales company. And again, the value of such a sales markup is usually significantly lower than that for the Guarantee supplier, or in any case cannot exceed it, since it is prohibited by law.

\section{Discussion}

The research results of the main methods of consumer influence on the final price of consumed electric energy are presented above in an overview, these methods are already actively used by experienced participants of the market. We propose to consider another way to control the value of the electrical energy cost as part of the discussion of the research results, which is a kind of derivative from the basic methods discussed at the beginning of the article. We are talking about the possibilities of using your own generation to compensate for local load peaks.

It would seem that this most obvious measure should have been placed at the very beginning of the article to avoid a detailed description of all other methods since its own generation can deprive the consumer of worrying about following the market specifics and form a clear and long-term understanding of the cost of electric energy. However, the world is changing rapidly, and to make your production depends on a single source of energy can be both dangerous in terms of reliability and expensive in terms of costs - at some moments, supply on the electricity market may be more profitable than own generation.

Moreover, the article is aimed specifically at considering ways to manage the cost of electricity in the retail market, and not at finding alternative ways to obtain a resource. Therefore, it is proposed to consider ways of using own generation specifically to control the market price for the consumer.

It is not by chance that this method was called derivative in the work, because it will work on the "basic" approaches to price management already described above.

As already described earlier, when using two-part tariffs in the calculations, the determination of the volumes of "Transport" and "Generator" capacities occurs on working days during peak consumption hours, and in addition, it was noted that the hours at which the value of the "Generator" capacity is determined are almost always in the range of hours 
in which the value of the "Transport" capacity is determined. Thus, using the capabilities of the own generation, it is possible to plan a calendar year for compensation of its peak consumption using own generation, which will reduce the amount of "Transport" and "Generator" capacities presented for payment.

Most often, when discussing the own generation, the issues of comparing the cost of the own generation of electricity and its purchase in the external market are considered, with a positive balance in favor of the own generation, the consumer is inclined to completely disconnect from the external network, and with a positive balance in favor of the external market, the issue of the own generation is often removed from the agenda altogether. However, the proposed method allows us to look at the prospects of the own generation from a new perspective: savings on the final price can create conditions for payback even for generation, which produces more expensive electricity than the market.

Several technical solutions for the own generation ensure the generation of electricity significantly below the market price, in particular, such as own gas turbine power plants, which can offer the cost of electricity 2-3 times cheaper than the market (10). Among other things, this is due to the fact that gas tariffs in Russia are growing more slowly than electricity tariffs. However, it is not always possible to purchase gas on an industrial scale for own generation, and other energy sources can't offer such significant savings. Thus, in one of the most developed countries in terms of renewable energy sources - the United States, the cost of generating electricity at the most popular RES facilities (renewable energy sources) in 2019 was distributed as follows (11):

Table 3. The cost of electricity depending on the type of generation.

\begin{tabular}{|c|c|c|}
\hline No. & Generation type & Electricity cost \\
\hline 1 & Solar photovoltaic installations & $\begin{array}{c}\$ 0.068 / \mathrm{kWh} \\
\text { (about } 5 \mathrm{RUB} / \mathrm{kWh})\end{array}$ \\
\hline $20,000,000$ & Onshore wind power & $\begin{array}{c}\$ 0.053 / \mathrm{kWh} \\
\text { (about } 4 \mathrm{RUB} / \mathrm{kWh})\end{array}$ \\
\hline 3 & Concentrated solar power & $\begin{array}{c}\$ 0.182 / \mathrm{kWh} \\
\text { (about } 13.6 \mathrm{RUB} / \mathrm{kWh})\end{array}$ \\
\hline
\end{tabular}

The indicators in the Kaliningrad Region are not so optimistic, according to some sources, the cost of electricity generation at the wind generators of the wind farm in Ushakovo is about 8 rubles per $\mathrm{kWh}$, which, taking into account transportation costs, cannot compete with market tariffs at any voltage level. The average tariff in one-part terms is about $5.3 \mathrm{RUB} / \mathrm{kWh}$ for January 2021, which, at first glance, shows the senselessness of creating own RES installations.

Perhaps that is why the spread of RES as an alternative to the retail electricity market in Russia is very small: only $0.15 \%$ of electricity is generated at RES facilities (12). From the data mentioned above, it can be concluded that currently, only gas turbine generation is a real alternative to electricity purchased on the retail market, however, when revising the approach to the use of renewable energy facilities specifically to compensate for peak loads, the reasons for creating own generation based on renewable sources can become more significant.

Detailed calculations using real load curves will be considered in future studies, however, to understand the possible effect, we point out that our capabilities for cost management are used extremely ineffectively right now: the maximum load comes to peak hours, and the main consumption is carried out during the daytime, for example in January 2021 in the Kaliningrad Region, the incremental cost of electricity for the consumer could reach 13 rubles per $\mathrm{kWh}$, when using two-part tariffs, therefore, the use of renewable energy facilities to compensate for maximum loads, even at a cost price of 8 rubles $/ \mathrm{kWh}$, could create a positive economic effect. 


\section{Conclusion}

Thus, the current pricing toolkit in the electric energy and power market gives the consumer ample opportunities to control the unit costs of electric energy in the final cost of the product, but very few really large enterprises use these opportunities.

The practical significance of the research results presented in this article lies in the fact that they can be used as a theoretical basis for creating a system for managing the costs of electric energy at enterprises, as well as for solving existing problems in the formation of the production cost price of an enterprise.

The research results presented in this article are aimed at informing consumers about possible technical and management solutions that can help reduce energy costs at their enterprises.

\section{References}

1. Energy Bulletin of the Analytical Center for the Government of the Russian Federation Issue No. 15, July 2014;

2. EU Energy Prices and Costs Appendix 5 Industry Case Studies By Nele Friedrichsen, Andrea Herbst, 31 March 2016;

3. Electricity Regulation in the Russian Federation: An Overview by Jennifer Josephson and Alexandra Rotar, Morgan Lewis. https://uk.practicallaw.thomsonreuters.com/6527-2969? transitionType $=$ Default $\&$ contextData $=($ sc. Default $) \&$ firstPage $=$ true

4. Production and consumption of electricity in the Russian Federation in 2017. https://1 prime.ru/sience/20181115/829538943.html;

5. Wholesale electricity and capacity market, NP Market Council Association. https://www.np-sr.ru/ru/market/wholesale/index.htm

6. Order of the Service for State Regulation of Prices and Tariffs of the Kaliningrad Region dated 30.12.2020 No. 138-01e / 20 and Order of the Service for State Regulation of Prices and Tariffs of the Kaliningrad Region dated 30.12.2019 No. 154-08e / 19;

7. Official site of JSC "System Operator of the Unified Energy System". https://www.soups.ru/news/newonsite-view/news/15519/;

8. Clause 23 of the Decree of the Government of the Russian Federation of December 27, 2010 N 1172 (as amended of March 18, 2021) "On approval of the Rules for the wholesale electricity and capacity market and on amendments to some acts of the Government of the Russian Federation on the organization of the functioning of the wholesale electricity market and power ";

9. Andrey Zhukov, Competitive Model. By 2026, there will be 3 times more own energy sources than centralized ones. https://www.dp.ru/a/2020/02/11/Konkurentnaja_model;

10. International Renewable Energy Agency: IRENA, Renewable Power Generation Costs in 2019. https://www.irena.org/publications/2020/Jun/Renewable-Power-Costs-in-2019

11. The main characteristics of the Russian electric power industry. The website of the Ministry of Energy of the Russian Federation. https://minenergo.gov.ru/node/532 